\title{
Quantification of pulmonary inflammation in experimental ARDS using static vs. dynamic positron emission tomography
}

A. Braune ${ }^{1}$; A. Güldner ${ }^{1}$; T. Bluth ${ }^{1}$; T. Kiss ${ }^{1}$; T. Koch ${ }^{1}$; M. Gama de Abreu ${ }^{1}$

\section{Background}

Positron Emission Tomography (PET) imaging using ${ }^{18} \mathrm{~F}-\mathrm{FDG}$ followed by mathematical modelling of the pulmonary uptake rate of ${ }^{18} \mathrm{~F}-\mathrm{FDG}\left(\mathrm{K}_{\mathrm{i}}\right)$ has been used for the assessment of pulmonary inflammation in experimental studies of the acute respiratory distress syndrome (ARDS). However, dynamic PET covers only a $15 \mathrm{~cm}$ cranio-caudal field of view and requires 60 75 min (Figure 1). It has been shown in patients with liver metastasis that $\mathrm{K}_{\mathrm{i}}$ values are highly correlated with tumor-toblood standard uptake ratios (SUR), derived from one frame of a 60min dynamic ${ }^{18} \mathrm{~F}-\mathrm{FDG}-\mathrm{PET}$ scan [van den Hoff et al., EJNMMl Research 2013;3(1):77]. We investigated whether $\mathrm{K}_{\mathrm{i}}$ values derived from dynamic ${ }^{18} \mathrm{~F}-\mathrm{FDG}$-PET correlate with SUR derived from static ${ }^{18} \mathrm{~F}$-FDG-PET in experimental ARDS.

\section{Methods}

- 12 pigs

- Induction of lung injury (lung lavage + injurious ventilation)

- Imaging sequences after injury (day1) and after

$24 \mathrm{~h}$ of mechanical ventilation (day2) including (Figure 2):

$>$ Computed tomography

$>$ Dynamic PET scan after injection of ${ }^{18} \mathrm{~F}-\mathrm{FDG}$,

$>$ Static PET scan (77-80min after ${ }^{18}$ F-FDG injection)

- Analysis of imaging data:

$>$ Dynamic PET scans: Patlak graphical analysis; voxelwise calculation of ${ }^{18} \mathrm{~F}-\mathrm{FDG}$ uptake rates $\left(\mathrm{K}_{\mathrm{i}}\right)$; mean $\mathrm{K}_{\mathrm{i}}$ values for 5 ventro-dorsal ROIs

$>$ Static PET scans:

voxelwise calculation of standard uptake ratios (SUR) for field of view of static PET scan using interpolated plasma activities: $\quad \operatorname{SUR}(T)=\frac{\mathrm{C}_{P E T}(t=T)}{\mathrm{C}_{\text {Plasma }}(\mathrm{t}=\mathrm{T})}=\frac{\text { Lungen }-\mathrm{SUV}}{\text { Plasma }-\mathrm{SUV}}$ calculation of mean SUR values for the same 5 ventrodorsal ROIs as used for Ki analyses

- Linear regression of $\mathrm{K}_{\mathrm{i}}$ and SUR of all regions and animals $(n=60)$ on day1 and day2; comparison of coefficients of determination $\left(\mathrm{r}^{2}\right)$

- Analysis of ${ }^{18} \mathrm{~F}-\mathrm{FDG}$-activity in blood plasma ( $\left.\mathrm{C}_{\text {Plasma }}\right)$

$>$ Sampling at mean frame timepoints of dyn. PET

$>$ Time-averaging of $\mathrm{C}_{\text {plasma }}$ for each animal and day $(\mathrm{n}=24)$

$>$ Comparison of $\frac{\int_{t=0}^{T} C_{\text {Plasma }}(t)^{*} d t}{C_{\text {Plasma }}(T)}$ at timepoint of static PET scan

\section{Results}

- Linear correlation of SUR and $\mathrm{K}_{\mathrm{i}}$ within all ROls: day1 ( $r 2=0.83)$; day2 ( $r 2=0.96)$; (Figure 3)

- The time-averaged plasma ${ }^{18} \mathrm{~F}-\mathrm{FDG}$-activities exhibited an essentially invariant shape across all animals and timepoints (Figure 4), as indicated by very little deviation from the group-averaged curve $\left(r^{2}=0.99\right)$

$\rightarrow$ Similar $\frac{\int_{t=0}^{T} C_{\text {Plasma }}(t)^{*} d t}{C_{\text {Plasma }}(T)}$ at timepoint of static PET: $154 \pm 14 \mathrm{~min}$

\section{Conclusion}

For quantification of pulmonary inflammation in experimental ARDS, SUR determined with static PET scanning is a valuable and faster alternative to dynamic PET scanning and Patlak analysis. The relatively high correlation between SUR and $\mathrm{K}_{\mathrm{i}}$ is likely explained by low inter-study variability of the plasma input function among animals and timepoints.

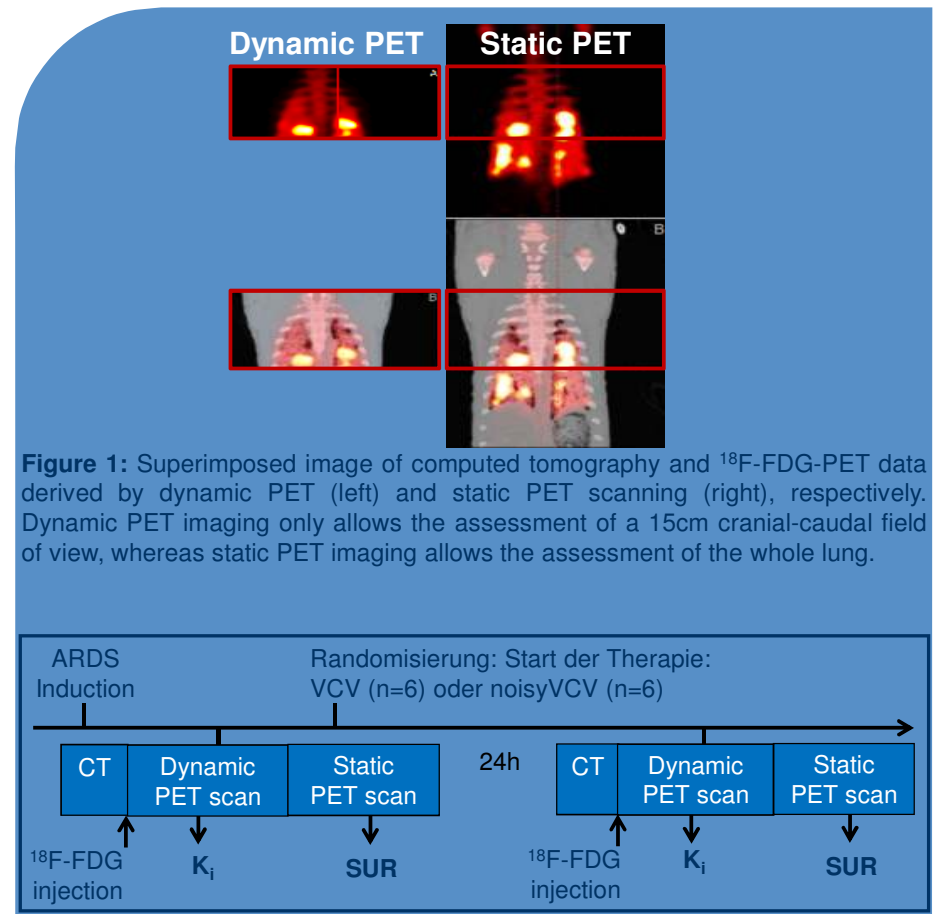

Figure 2: Time course of imaging and analysis of imaging data.

Patlak Equation

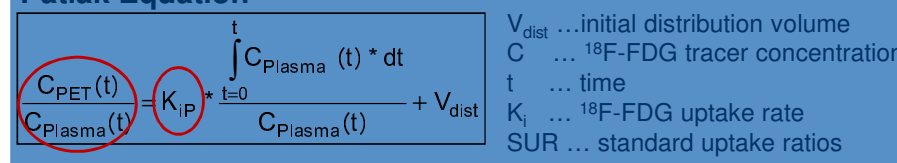

SUR $\sim \mathrm{K}_{\mathrm{i}}$
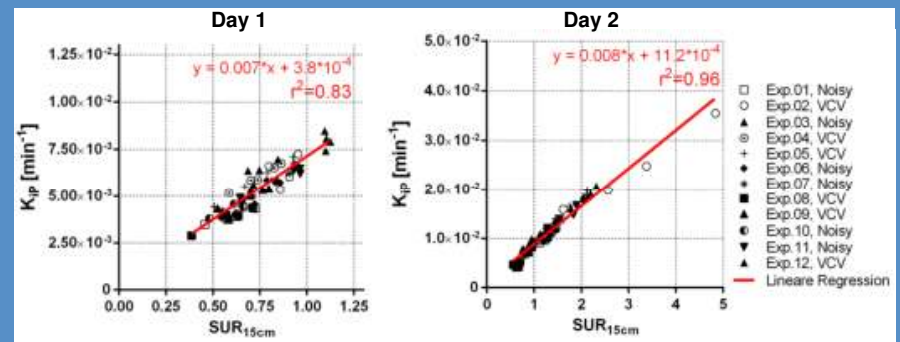

Figure 3:

PET scanning, and of the metabolic ${ }^{18} \mathrm{~F}-\mathrm{FDG}$ uptake rate according to Patlak $\left(\mathrm{K}_{\mathrm{i}}\right)$, assessed by dynamic PET scanning, on the 1. experimental day (left) and on the 2. experimental day (right).

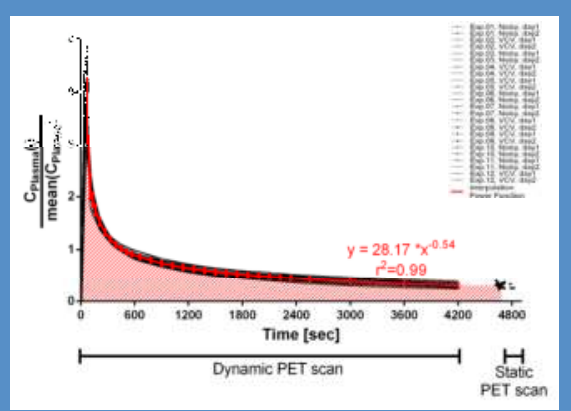

Figure 4: Time course of the ${ }^{18} \mathrm{~F}-\mathrm{FDG}$ activity in blood plasma ( $\mathrm{C}_{\mathrm{Plasm}}$ ) normalize to the respective mean value shown for all 12 animals and both experimental days. Red: Interpolation for samples taken during the period of the dynamic PET scan. 